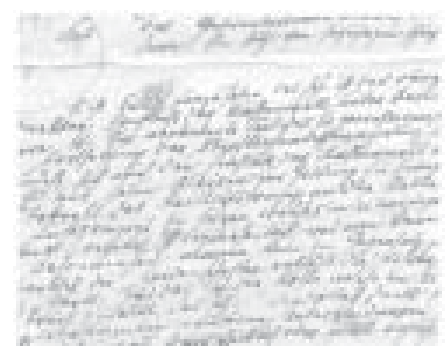

\title{
Tarrafa de pescaria: o uso de carta na pesquisa
}

Ana Alcídia Araújo Moraes ${ }^{1}$

MORAES, A. A. A. Fishing cast net: the use of letters in a study. Interface - Comunic., Saúde, Educ., v.10, n.19, p.169-84, jan/jun 2006.

The text shares an experience in which letters were used as one of the means for collecting information for an investigation. The period of investigation went from 1996 to 1997 and involved 16 letters sent by the researcher and 13 letters received in response from the research subjects. Letters, missives or epistles are a resource rarely used in research, though some studies report that lately their use has been growing. The letters collected in this study reflected a crisscrossing of reader-professor histories, as they were sometimes similar and sometimes different, in the natural movement of histories that were also underscored by other voices and by different times, spaces and transposed pathways. The use of letters showed itself to be a generator of links of enchantments, of the crisscrossing of affective and cultural relationships between the investigator and the professors and a self-education alternative.

KEY WORDS: correspondence. teaching. education. research methodology.

Analisa-se uma experiência que usa a carta como um dos recursos de coleta de informações em pesquisa. 0 caminho percorrido, no período de 1996 a 1997, envolveu 16 cartas enviadas pela pesquisadora e 13 cartas como respostas das professoras que representavam os sujeitos investigados. A carta, missiva ou epístola ainda tem sido um recurso pouco utilizado na pesquisa, embora alguns estudos dêem conta de que mais recentemente seu uso venha crescendo. As cartas, recolhidas pelo movimento da pesquisa desenvolvida, trouxeram à tona um entrecruzamento de histórias de leitoras-professoras que, em alguns momentos, assemelham-se e, em outros, diferenciam-se, num movimento natural de histórias que são marcadas também por outras vozes e por diferentes tempos, espaços e trilhas percorridas. O uso da carta revelou-se, assim, como um gênero que estabeleceu elos de encantamentos, entrecruzamento de relações afetiva e cultural entre a pesquisadora e as professoras, e alternativas de autoformação.

PALAVRAS-CHAVE: correspondência. ensino. educação. metodologia de pesquisa.

1 Professora, Centro de Desenvolvimento do Ensino Superior em Saúde, Universidade Federal de Sâo Paulo, Cedess/Unifesp, SP; Faculdade de Educação, Universidade Federal do Amazonas, AM. <alcidia@cedess.epm.br>

${ }^{1}$ Rua Tucuna, 913 , apto. 45

Perdizes - São Paulo, SP

Brasil - 05.021-010 


\section{Situando o contexto da pesquisa}

O presente texto relata uma experiência de pesquisa ${ }^{2}$ que usa a carta como um dos recursos de coleta de informações. A referida pesquisa, utilizando-se da narrativa de histórias de vida como instrumento de investigação, buscou conhecer as histórias de leitura de professoras que exercem a docência na cidade de Parintins-AM.

A alternativa de usar a carta para esse fim foi motivada, principalmente, por dois aspectos: um deles, o meu desejo de realizar a pesquisa voltada para o contexto amazônico, meu lugar de atuação profissional; o outro, por ser este um lugar ainda pouco pesquisado no campo da educação.

Nesse cenário, tentei arquitetar uma estratégia que possibilitasse resolver o impasse em que me encontrava, cursando doutorado em São Paulo e querendo fazer a pesquisa no município de Parintins, no Estado do Amazonas.

Pelo cronograma da pesquisa, a coleta de dados estava prevista somente para 1997. Até lá, eu estaria cumprindo créditos e a distância geográfica tornava bem concreta a separação espaço/tempo que me afastava do contexto da pesquisa, Parintins/AM.

A cidade de Parintins fica a $420 \mathrm{~km}$ de Manaus. Tem o relevo natural e exótico de uma ilha, com 7.069 km de superfície, situada à margem direita do Rio Amazonas, e formada pelo Paraná do Limão, Anhinga, Redondo, Lagoa Francesa, Lago do Paranapanema e Lago do Macurany; é cercada pelas águas amareladas-barrentas do rio Solimões.

Uma das poucas e a mais importante via de acesso que liga Manaus a este município é o transporte fluvial. Descendo o curso do rio, de barco, até Parintins, é possível observar vários fenômenos próprios da Região Amazônica: o "Encontro das Águas" é o primeiro fenômeno natural que ornamenta a paisagem de um lugar esculturado pela confluência das águas do Rio Negro com as águas do Rio Solimões.

Os arredores da ilha guardam uma beleza extravagante: a Serra de Parintins, formação rochosa de cerca de $152 \mathrm{~m}$ de altitude, de onde é possível vislumbrar a Floresta e o Lago da Valéria, com uma vegetação típica da região amazônica - a "Vitória Régia". Na época da vazante, surgem lindas praias às margens do rio Uaicurapá. Mas para descrever o cenário geográfico, com a propriedade de quem tem laços mais firmes com o enredo do lugar, nada melhor do que uma filha da terra:

A cidade de Parintins fica numa das Ilhas Tupinambarana, a cidade, o município todo está incluído no Arquipélago Tupinambarana, o município está dentro do arquipélago. Parintins limita-se com o Estado do Pará, com o município de Nhamundá, de Urucará, um trecho de Barreirinha e Urucurituba. Parintins é o centro de toda essa região aqui, de todas as cidades e municípios em volta, porque fica bem localizada, fica num lugar estratégico da situação geográfica. É uma Ilha cercada de dois lagos, Macurany e Parananema, a Lagoa da Francesa e, na frente, o Rio Amazonas. Os municípios mais próximos daqui são Barreirinha (duas horas e meia, três horas) e Nhamundá (quatro horas de viagem). (Pacheco) 
Naquele momento, meu maior desafio, enquanto pesquisadora, era criar possibilidades que, de algum modo, me permitissem uma primeira aproximação com esse lugar. Para Demo (1985), a tarefa de pesquisar exige, do(a) pesquisador(a), criatividade, pois pesquisa envolve a técnica, mas igualmente é arte. As sugestões metodológicas são importantes à medida que favorecem a criação da pesquisa. Nesse sentido, o autor alerta que:
A metodologia é somente instrumento para chegarmos lá.
Discutimos os caminhos possíveis, os já vigentes, os que poderíamos inventar, os discutíveis, os que já se superaram, e assim por diante. Não vale a pena entreter-se de tal modo com questões metodológicas que não cheguemos a fazer a pesquisa.. (Demo, 1985, p. 22)

Seguindo essa perspectiva sugerida pelo autor, comecei então a "ruminar" idéias para ultrapassar os percalços resultantes da distância. Sabia que, somente por telefone, ficaria inviável uma aproximação mais fiel/concreta com o contexto investigado. Como já havia estabelecido alguns contatos por meio de cartas com uma das professoras, agarrei-me ao recurso da prática epistolar como via de acesso para adensar minha comunicação também com as outras três.

Minha intenção inicial era usar as cartas como um recurso que me possibilitasse uma espécie de um primeiro contato com as minhas parceiras de pesquisa, uma necessária ( $r$ e) aproximação com essas professoras (exalunas), antes de poder estar com elas pessoalmente para realizar a entrevista. Agindo assim, pensei que conseguiria reduzir as distâncias entre a pesquisadora e o contexto da pesquisa - escrever e receber cartas foi a fórmula (naquele momento até encantadora) de começar a estabelecer uma relação com aquelas que seriam as minhas parceiras na pesquisa que se iniciava.

No vaivém das cartas, fui percebendo que elas eram portadoras de um conjunto de informações que me estimulavam a intensificar o fluxo das correspondências e que, ao mesmo tempo, me faziam refletir sobre a legitimidade do uso das cartas como um instrumento de pesquisa, tendo em vista que esse uso implica situar a carta em um espaço que não é o espaço da intimidade, onde comumente a escrita de carta se constrói. A inquietação levou-me a uma busca bibliográfica com o propósito de encontrar algum respaldo para minha intenção de usar as cartas como estratégia de coleta de dados para a pesquisa.

\section{A carta: (re)conhecendo a diversidade de seus usos}

Já faz algum tempo que o mercado editorial brasileiro tem lançado publicações portadoras de escritos epistolares. A divulgação desses escritos é reveladora do conteúdo intimista e privativo que as cartas carregam, uma vez que se tornam do conhecimento público fatos, episódios e aspectos desconhecidos e antes restritos ao domínio dos correspondentes, em algumas situações, pessoas anônimas. Este é o caso, por exemplo, da 
publicação de um conjunto de cartas que Mário de Andrade enviou a vários de seus interlocutores, fato que o revela como um missivista constante. Dentre os interlocutores que trouxeram a público as suas cartas, podemos citar os nomes de: Manoel Bandeira (1958 e 1967), Carlos D. de Andrade (1981), Fernando Sabino (1981), Oneyda Alvarenga (1983) e Anita Malfatti (1989). Vale lembrar que essas cartas, originalmente, não tinham a publicação de seu teor (privado) como horizonte de destinação, uma vez que havia um destinatário bem demarcado que, certamente, não pressupunha o grande público como seus leitores (destinatários). Além disso, o teor desses escritos epistolares não se destinava a servir como objeto de análises ou subsídio de investigação.

Nessa busca bibliográfica, além desses escritos que versam sobre cartas, tive acesso à pesquisa de doutorado de Santos (1994), que se debruça sobre o tema em questão, analisando aspectos conceituais, normativos e éticos, bem como o uso desse meio de comunicação na literatura. Também encontrei o estudo de Rocha (1997), "Abelardo-Heloísa: cartas", sobre a correspondência entre Abelardo e Heloísa, relatando fragmentos de suas histórias de vida, aventuras, desventuras e as vicissitudes do drama de amor que os dois viveram. Por intermédio das missivas, o autor consegue apresentar o contexto histórico-cultural em que se dava a comunicação entre os dois. O trecho a seguir pode dar uma breve idéia sobre isso:

As cartas mostram claramente que Abelardo e Heloísa viveram suas vidas em dois grandes mundos: o mundo das Escolas e o mundo dos Mosteiros. Pois bem, o renascimento cultural e religioso do século XII modificou profundamente as estruturas destes dois mundos. (Rocha, 1997, p.42)

A carta, missiva ou epístola permite a comunicação manuscrita ou impressa com uma ou várias pessoas que estejam (em geral) distantes/ ausentes do lugar e do tempo de onde se escreve. $O$ ato de escrever cartas sempre (ou quase sempre) traz consigo a preocupação de ser entendido ou, mesmo, a insegurança e a vergonha de escrever para alguém que, do outro lado do papel e de um outro espaço geográfico, vai penetrar nas palavras, nos sentidos das narrativas e nas histórias de vida de quem escreveu. Para o autor-escritor da carta, existe sempre um leitor-destinatário situado em um determinado espaço-tempo histórico. Por isto, quem escreve sempre tem presente questões dessa ordem: para quem se escreve; o que escrever; como escrever para ser entendido; o que pode ser escrito/partilhado com o outro; o lugar-tempo de onde se escreve e para o qual se escreve.

A carta é um gênero primário do discurso propício para refletir a individualidade daquele que escreve. Ela pode permitir, de forma bastante demarcada, a passagem da palavra do autor para o seu destinatário. A alternância de falantes ocorre porque se trata de um gênero mais próximo da oralidade e, por isso, permite a quem escreve dizer tudo aquilo que queria dizer, de tal forma que, ao ler, o destinatário percebe um acabamento do querer dizer do autor e, segundo os estudos de Bakhtin (1997, p.290), simultaneamente adota uma "atitude responsiva" em 


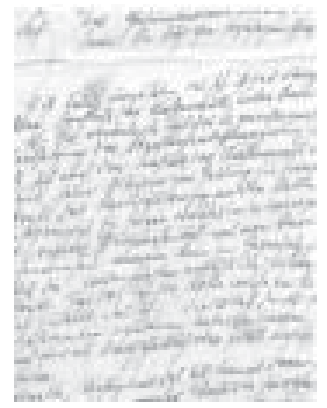

relação à provocação feita por este - discorda, concorda, complementa, afirma, opõe, consente, reage.

$\mathrm{Na}$ carta, essa atitude responsiva do leitor-destinatário pode ser retardada pela característica que o gênero oferece - o autor escreve de um lugar e tempo determinado e o destinatário lê de um outro lugar e em outro tempo. Por isto, a resposta esperada pelo autor não acontece de imediato, como ocorre em outro diálogo em que destinatário e autor estejam num mesmo espaço/tempo.

A carta ainda tem sido um recurso pouco utilizado na pesquisa, embora alguns estudos dêem conta de que mais recentemente seu uso venha crescendo. Uma investigação muito interessante, que talvez possa ser situada como um marco inicial da utilização de cartas como instrumento de coleta de dados, é a de Demartini (1988). Seu texto, intitulado Histórias de vida na abordagem de problemas educacionais, relata o processo de investigação das memórias de professores que lecionaram durante a Primeira República no Estado de São Paulo, discutindo o uso das cartas como uma alternativa de realização da pesquisa:

\section{[...] como nem sempre dispúnhamos dos telefones dos professores indicados, e também porque ligações interurbanas para todos eram inviáveis aos custos da pesquisa, resolvemos estabelecer contatos com os mesmos inicialmente através de cartas nas quais explicávamos o objetivo da pesquisa e solicitávamos a colaboração; pedíamos que escrevessem contando sobre sua vida e especialmente sobre alguns aspectos que para nós eram importantes. (Demartini, 1988, p.53-4)}

Este trecho dá pistas de que lançar mão das cartas foi a via que se apresentou, naquela situação, como a única possível para levar a pesquisa adiante. Começar a corresponder-se, com os professores, por cartas foi a possibilidade viável (em comparação com os custos que um outro movimento acarretaria) para estabelecer contatos com os pesquisados, dispersos pelo interior de São Paulo. Mas o relato da autora (1988) testemunha que a troca de cartas, além de revelar-se como estratégia extremamente importante para a pesquisa, também trouxe momentos de encantamento para as pessoas envolvidas no processo da pesquisa.

O escritor de cartas pode estimular um jogo de perguntas e respostas dialogando com o leitor - formula perguntas, responde-as, opõe objeções, refuta idéias; deduz o querer dizer do outro e faz novas perguntas a partir da provocação. Assim, fica estabelecida uma dinâmica de comunicação em que a resposta do seu interlocutor é uma possibilidade presente-ausente, próxima-distante, ainda que emudecida por algum tempo. Talvez por isto a carta seja um gênero que estabelece elos de encantamentos mágicos e sedutores, podendo entrecruzar relações afetivas e culturais entre as pessoas.

Uma outra pesquisa que faz uso da prática epistolar é a de Vencio (1996), que relata a experiência do povo Jarawara com a escrita de cartas. O estudo destaca a troca de cartas entre esses índios como uma alternativa 
que possibilita mudanças na educação escolar indígena, que historicamente vem sendo marcada pelo modelo de escola do não-índio. Nessa perspectiva, a autora enfatiza que:

A modificação mais profunda que fizeram foi a mudança da função que receberam para a escrita através da substituição do livro didático impessoal, pré-elaborado, que foi trocado pela CARTA, que se tornou o Livro Didático Jarawara, pessoal e em constante elaboração. A carta se tornou o meio e o fim do letramento. Além disso, criaram a CARTA JARAWARA, tendo como característica principal o fato de ser escrita por uma pessoa em particular mas lida por todas. (Vencio, 1996, p.4)

\section{A prática epistolar na pesquisa com professoras de Parintins} $\mathrm{Na}$ pesquisa em foco, escrever cartas foi uma possibilidade de narrar experiências vividas e permitiu abrir um diálogo entre a pesquisadora e as professoras-participantes, estabelecendo-se como uma das fontes de informações para essa investigação, que se utilizou também das narrativas orais.

Neste sentido, para suscitar a atitude responsiva nas minhas parceiras de pesquisa, sabia que precisaria utilizar-me de artifícios estratégicos da escrita capazes de seduzir, convencer, provocar e catucar, instigando-as à troca de cartas, permitindo-me, assim, adentrar sutilmente nas suas histórias de leitura. Em relação a isso, é interessante o que Neves (1988 apud Nunes \& Carvalho, 1993) explica sobre a teoria da carta, tratando-a com base em questões que coloca sobre sua constituição, estatuto, cronologia, entre outros aspectos. Neves (1988), ao se perguntar o que constituiria uma história da carta, remete-se a diferentes possibilidades de leitura que a mesma encerra, tais como:

[...] às relações de regras de reciprocidade (análise de envios e respostas); aos temas favorecidos pelo uso desse suporte; às características de sua materialidade; aos critérios que presidem a sua guarda ou destruição; ao seu caráter de 'encaixe' em séries materiais ou epistêmicas; à variedade construída dentro desse gênero (a carta a desconhecidos, a si mesmo, a qualquer pessoa, a carta aberta, a carta que só pode ser aberta em certa situação, a carta a amigos etc...); à análise quanto aos ritos de tratamento, interpelação, regras de polidez [...].

(Nunes \& Carvalho, 1993)

O processo de correspondência que tentava dar início trazia-me algumas preocupações que, de certo modo, iam ao encontro das indicações de Neves (1988) pois, ao iniciar a escrita das cartas destinadas às minhas amigas, levantava questões/preocupações mais centradas no que e no como escrever, para não tornar a leitura enfadonha e, ao mesmo tempo, ser bem compreendida nos meus objetivos: corresponder-me para recolher dados que seriam úteis para a pesquisa.

174 Interace- Comunic, Saúde, Educ, v.10, n.19, p.169-84, jan/jun 2006 
${ }^{3}$ Trechos de uma carta que enviei às professoras, de São Paulo a Parintins, em 13 de junho de 1996.
Pensando um pouco nisto, procurei escrever numa linguagem informal e amistosa, tentando fazer (e querendo) com que as minhas leitorasdestinatárias se sentissem à vontade para ler, e que, principalmente, gostando da leitura, se colocassem também à vontade para escrever com descontração sobre qualquer assunto que desejassem partilhar comigo. Além do caráter informal que procurei dar às cartas, também, vez por outra, usava alguns trechos literários, tentando embelezar meus escritos, embalada por outras vozes, entoando outros coros de palavras já antes decantadas em diferentes contextos, textos e intertextos, enunciadas por diversos autores, de modos, maneiras e lugares diferentes.

Assim, com essas preocupações, dei início à minha prática epistolar com as professoras que habitam a Ilha de Parintins, localizada no Estado do Amazonas. As cartas parecem ter esse poder mágico: fala-se com quem não está presente e consegue-se chegar (às vezes demorando uma semana) em lugares onde a nossa imaginação (e outros meios de comunicação mais modernos) chega bem mais rápido.

Na primeira carta para as três professoras, inicialmente, senti-me desafiada, como escritora-autora, a seduzir cada uma das minhas leitoras, conquistando a sua aquiescência definitiva para participar da pesquisa (tinha receio de que recuassem no aceite que havia ficado garantido por telefone). O segundo desafio que tinha pela frente era conseguir deixar claro (sem amendrontá-las) o que seria o trabalho e qual seria a participação das mesmas. Imbuída deste propósito, tentei, nesse (re)encontro de conversas escritas ou (re)encontro de manuscritos ou ainda (re)encontro epistolar, envolvê-las em minhas lembranças saudosas do lugar e das pessoas que ali habitam; reafirmei o prazer de poder fazer o trabalho lá e assim poder revê-las; falei do meu interesse (mais que isso paixão) pela temática - leitura e formação de professor.

Além de ressaltar a importância de um trabalho em que o professor narre a sua própria história de formação - e daí a necessidade da participação das mesmas na pesquisa -, utilizei-me de algumas palavras do poeta amazonense Thiago de Melo (1975), para embalar minha conquista premeditada, expressas nesse pequeno trecho ${ }^{3}$ da primeira carta enviada:

\footnotetext{
A familiaridade com esse lugar e com as pessoas daí dá uma marca de identidade a essa pesquisa, despertando-me um sentimento que me remete ao que nos fala o poeta Thiago de Melo: "Piso firme no meu chão, sei que estou no meu lugar, como a panela no fogo e a estrela na escuridão.

Iniciei com o poeta Thiago de Melo e quero finalizar esse nosso primeiro encontro com as suas palavras que, ao meu ver, retratam a importância de um trabalho que tente tornar o professor o contador de sua própria história: “O que passou não conta?, indagarão as bocas desprovidas. Não deixa de valer nunca. o que passou ensina com sua garra e seu mel. Por isso é que agora vou assim no meu caminho. Publicamente andando.
} 
A estratégia das cartas, enquanto instrumento de coleta de informações para a pesquisa, deixou-me em diversos momentos intranqüila em razão do tempo que demorava para receber as respostas. Algumas demoravam até mais de um mês para chegar - a tarrafa ${ }^{4}$ enroscou-se diversas vezes no fundo do rio - e foram necessárias diversas fisgadas (telefonemas) para conseguir desenroscar a rede lançada. Isso vem confirmar que a pesquisa tem suas dificuldades e limitações impostas pela sua própria natureza. E, neste caso específico, enfrentava um obstáculo, até certo ponto, "grande", mas que lhe é quase intrínseco: o fato de usar como um dos instrumentos para registrar as histórias das professoras a prática epistolar, o que exige, por parte das narradoras, um exercício solitário de auto-r eflexão, fazendo-as voltarem o olhar para as suas histórias de práticas de leitura, modos/ maneiras de ler e materiais lidos. Afora isso, a tar efa de organizar as idéias para escrever pode demandar algum tempo porque não é algo tão simples, pelo menos para a maioria das pessoas. Para essas professoras, também parecia mais fácil relatar oralmente do que escrever, tanto que, em alguns diálogos mantidos por telefone, elas falavam sobre trechos de suas histórias (indagados nas cartas) com muita desenvoltura e, ao contar oralmente, elas queriam considerar como respondidas as cartas que recebiam. Tentei compreender e aceitar a demora nas cartas-respostas como uma dificuldade, até certo ponto, inclusa nos planos de uma pesquisa que usa a prática epistolar como instrumento de investigação. ${ }^{5}$

Num espaço de um ano e três meses (março/1996 até junho/1997), escrevi, ao todo, dezesseis cartas para as minhas parceiras: pedindo novas informações e também reforçando o pedido de informações já solicitadas em cartas anteriores. E, a partir de abril de 1996 até julho de 1997, recebi, ao todo, de três professoras, treze cartas.

Durante esse período, tentei ir recolhendo respostas às seguintes provocações: a escola, a série e as disciplinas do magistério em que trabalhavam; o trabalho com as disciplinas em sala de aula; a leitura na infância (dentro e fora da escola); lembranças das experiências e momentos marcantes com a leitura em suas vidas; a formação enquanto leitora; influências da família e da escola na formação da leitora; leituras obrigatórias; acesso aos materiais escritos; influências da formação de leitora na atuação como professora; leituras mais recentes; formação acadêmica (do curso inicial aos mais recentes).

As cartas que chegavam traziam as seguintes preocupações sobre: para quem estavam escrevendo ( a amiga, mas também a ex-professora); o que e como escrever; e, possivelmente, que assuntos/aspectos poderiam ser contados/ partilhados por cartas. A preocupação com a apresentação da escrita, por estar escrevendo para a ex-professora, transpareceu principalmente na fala ${ }^{6}$ de duas delas: “Desculpa as falhas, pois estou fora de forma em escrever a máquina" (Socorro). "A máquina é velha e a datilógrafa pior ainda" (Pacheco).

À medida que recebia as cartas, ia organizando as informações, fichandoas com base nos focos temáticos que transpareciam das leituras das mesmas. Destaquei de cada carta focos que me orientassem como subtítulos; passei para o computador as informações, tomando o cuidado
${ }^{4}$ Tarrafa - rede de pescaria. Metáfora que utilizo referindo-me à pesquisa. Pescar pesquisar.

${ }^{5}$ Acresça-se a isto a questão da dependência de um serviço externo - os Correios - para garantir a entrega das cartas.

${ }^{6}$ Trechos de duas cartas, de diferentes sujeitos, enviadas para mim de Parintins-AM a São Paulo, uma datada de abril/ 96 e a outra de $17 /$ set/ 96 . 
de, ao usar fragmentos dos textos, não deslocá-los do contexto original da narrativa, ou seja, mesmo usando trechos em outros lugares, a meu ver, necessários para a minha própria orientação, deixá-los naqueles lugares dos relatos onde, naturalmente, apareciam. Nesses fichamentos, primeiramente, ia tentando perceber os temas em cada carta, depois, no conjunto de cartas de cada uma das professoras. Feito isso, fui procurando apreender os temas comuns nos três conjuntos que consegui compor. Os dados fichados por títulos temáticos foram me permitindo colocar novas indagações sobre a produção brasileira que vê o professor como um nãoleitor, e sobre a prática de leitura daquelas professoras, revelada naqueles relatos. Fui ampliando uma visão que contrastava com uma representação de que os professores não lêem.

Com a intenção de avivar as memórias e, assim, provocar lembranças das suas próprias histórias de leitura, enviei uma carta acompanhada de três textos: um de Paulo Freire - A importância do ato de ler (1993); outro de Ezequiel Silva - Literatura e pedagogia: reflexões com relances de depoimento (1990), e outro de Lygia Bojunga Nunes - Livro: eu te lendo (1990). Nestes textos, os autores contam episódios de suas histórias de leitura. Com essa estratégia, esperava fazê-las (re)viver, (re)passar o filme de suas histórias de vida para que pudessem (re)encontrar a boniteza contida também nas suas próprias histórias de leitura e formação.

Uma outra estratégia que utilizei para lançar (outra vez) a tarrafa no rio, ou seja, dar continuidade ao processo de construção da pesquisa, foi cruzar os trechos das histórias contidas nas cartas, para que o fragmento da história de uma mexesse com a história de outra, esperando desta maneira causar ressonâncias no sótão de lembranças adormecidas na memória. Com isto, pretendia especular a história de uma com os fragmentos da história das outras, tentando, assim, afinar um acorde de vozes (informações) içadas pela rede na correnteza do rio. Essa "artemanha" de que lancei mão para alcançar o não-dito sobre as histórias das professoras, que interessava para a pesquisa, remete-me ao que pondera Demo (1985) sobre a garantia da construção do conhecimento científico, por meio da pesquisa, como finalidade básica da ciência. Em relação a isso, o autor ressalta que o pesquisador precisa ser criativo:

Como em tudo na vida, a ciência não é ensinada totalmente, porque não é apenas técnica. É igualmente arte. E na arte vale a máxima: é preciso aprender a técnica, para termos base suficiente: mas não se pode sacrificar a criatividade à técnica; vale precisamente o contrário; o bom artista é aquele que superou os condicionantes da técnica e voa sozinho [...]. (Demo, 1985, p.22)

\section{(Re)encontro com as cartas}

Com o objetivo de encontrar um fio condutor que me alinhasse na construção de um instrumento para recolher informações em agosto/ 1997, quando pretendia estar com as professoras para entrevistá-las, fiz uma leitura do conjunto de todas as cartas que havia recebido. Essa 
releitura revelou-se como uma experiência de descoberta, de nova chamada de atenção para pontos que antes haviam passado despercebidos pelo meu olhar, num primeiro momento, atento para outras informações.

Comecei a perceber que as histórias daquelas leitoras-professoras, em algum momento (tempo/espaço), cruzavam-se com a minha própria história, também de leitora-professora. Nas suas narrativas, as três professoras lembravam a disciplina que eu havia ministrado no Curso de Licenciatura em Letras como um marco importante nas suas trajetórias de leitoras. Descubro-me, assim, como uma personagem nas suas histórias de formação de leitoras-professoras. Uma das falas expressa em uma das cartas que me permitiram esta descoberta foi a seguinte:

[...] eu não gostava de ler. Porém, ao ingressar no curso de graduação, tendo como primeira disciplina METODOLOGIA DO ESTUDO e ainda por cima tendo recebido uma literatura diferente das que vira anteriormente (livro didático), sofri um impacto devastador (...) És grande responsável por esta brusca mudança! ${ }^{7}$

Uma história sozinha, anônima, esquecida, silenciada e não revelada parece não ter significado, mas, quando é pensada e situada num determinado contexto de formação e é partilhada com outros parceiros, é possível perceber que, no entrelaçamento das histórias individuais, aparece uma dimensão coletiva que a constitui. Por esta razão, ao ler as narrativas contidas nas cartas, fui percebendo que nossas histórias representam um caminho perpassado por outras. São histórias aparentemente solitárias, mas construídas no coletivo dos "sentidos" de outras, de outros percursos que, ao se cruzarem quase despercebidamente, (se)construíram e (re)construíram cada trajetória individual contextualizada no coletivo de um mesmo espaço de formação - a escola, a sala de aula e para além delas.

Descobrir-me como personagem daquelas histórias me fez ver que as histórias de formação (minha e de outros) podem ajudar a formar outros, porque nos permitem não só refletir sobre aquilo que foi feito, mas fundamentalmente descobrirmo-nos como autores de uma trama que é tecida no conjunto de outras histórias de outros homens e mulheres (leitores-professores), histórias que se movem, que se parecem e se diferenciam, que se identificam e se confrontam. Enfim, percebermo-nos como construtores, e não só consumidores, de histórias que, assim como a rebeldia das águas, no banzeiro de um rio, não se movem linearmente em uma única direção. É justamente nessa história em construção que se insere e se movimenta a história da leitura e das professoras leitoras.

Outra informação que consider ei muito instigante foi revelada nos fragmentos de cartas de duas professoras:

[...] sobre minha vida de leitora, infelizmente não tenho muita história. A leitura propriamente começou em minha vida quando passei no vestibular e comecei o curso de Letras. Nesse período,
7 Trechos de uma carta que recebi de Parintins-Am, datada de 08 de julho de 1996. 
8 Trecho de uma cartafax da Socorro que recebi em nov/96

${ }^{9}$ Trecho de uma cartafax da Pacheco, recebida em nov/ 96 .

10 Depoimento recolhido em 1998. percebi que a leitura é um fato importantíssimo na vida de qualquer pessoa, sobretudo na vida de um professor. ${ }^{8}$ A minha história de leitora é como a da maioria dos brasileiros. Tem pouco a acrescentar. ${ }^{9}$

Estas duas falas podem estar revelando uma diluição das teias de uma história pessoal no conjunto de outras histórias. Isto fica mais transparente nesses relatos, quando o narrador silencia a sua própria história, referindo-a como desprovida de sentido ou significado. Como alguém que não se inclui como fazedor da história, porque a versão oficial parece silenciar as histórias do cidadão comum, ao mesmo tempo que cria estratégias de valorização do percurso de leitura de uma minoria de homens e mulheres socialmente denominados e reconhecidos como ilustres.

Além dessas revelações, outras também apareceram nos relatos das cartas: a formação acadêmica; aspectos do trabalho com a leitura em sala de aula; o desencanto e/ ou entusiasmo com a profissão; aspectos da constituição da leitora; influências da família na formação de leitora; momentos marcantes na vida da leitora, idéias a respeito do que vem a ser o leitor.

Em agosto de 1997, quando reli todas as cartas recebidas/ escritas, logo de início me chamou a atenção a alegria da carta de Pacheco, escrita há um ano, pela vitória do boi Caprichoso e a esperança, quase certeza, de que naquele ano de 1997 chegaria ao "tetra". Um ano de tempo vivido em troca de cartas e, naquela releitura, me deparava com a confissão de sua tristeza pela derrota do Caprichoso e a vitória do boi contrário, o Garantido.

Considero importante esclarecer que meu comentário sobre o que a Pacheco fala nessa carta refere-se a uma festa importante que ocorre no mês de junho, no município de Parintins-AM. Essa festa surgiu na década de 1930, quando os bumbás, cordões de pássaros e de peixes, além de pastorinhas, dançavam nas ruas em frente às casas. No entanto, com o passar dos anos, foi crescendo e, o que era uma brincadeira de rua, ganhou espaço físico próprio e dias fixos no calendário parintinense. A festa ganhou tamanha proporção, que, atualmente, os visitantes, durante os dias da festa, não são somente amazonenses mas também de outros Estados do Brasil e até de outros países. Sobre isso, a Pacheco nos conta que: “O Festival tem 32 anos, ${ }^{10}$ que é contado como festival oficial, isto é, em que há disputa entre o boi-bumbá Garantido e o boi-bumbá Caprichoso, disputa de títulos. Essa disputa entre os dois bois que levou a evolução do festival a essa explosão".

$\mathrm{Na}$ época do Festival Folclórico, a cidade veste-se de bandeiras azuis e de cor vermelha, e divide-se ao meio para demarcar as fronteiras de "Caprichosos" (azul/branco) e "Garantidos" (vermelho/branco). As cores expressam as preferências por um ou por outro boi. A paisagem da cidade ganha o colorido dessas cores: a fachada das casas e os ornamentos no seu interior; as roupas que as pessoas vestem; as bandeiras dependuradas nas ruas; o cais do porto, apinhado de barcos, dando o tom e o colorido festivo 
ornamentados de bandeiras. Enfim, durante a festa, moradores e visitantes vestem e cantam a paisagem da cidade de Azul (Boi Caprichoso) e Vermelho (Boi Garantido).

Aquela é uma festa diferente, entre outras coisas, porque enquanto um boi se apresenta, a torcida contrária assiste em silêncio, em atitude de respeito ao espetáculo que o boi contrário oferece. Ao mesmo tempo, do outro lado, a torcida simpatizante do boi que está se apresentando canta e dança numa euforia contagiante.

$\mathrm{Na}$ arena, chamada de Bumbodrómo, os brincantes representam mitos e lendas amazônicas, misturados a traços da cultura indígena e da vida do caboclo da região. As coreografias são marcadas por passos inspirados em danças indígenas. As músicas, chamadas de toadas, são verdadeiros poemas que decantam a beleza da Ilha e das culturas herdadas dos índios e dos caboclos da região.

Para mim, esse assunto sobre a derrota do Caprichoso, na primeira leitura das duas cartas, era apenas um dado da nossa intimidade aprisionado pelas nossas escritas, um dado que mereceu a minha atenção. Entretanto, na releitura, o assunto me parecia revelar a "pessoalidade" de alguém que (antes de ser uma informante da pesquisa) é minha amiga e, por essa razão, sentia a necessidade de partilhar um tema latente e pulsante como esse. Por isto, partilhava uma tristeza que sabia interessar (a mim), sua amiga (leitora-destinatária), por ser alguém que já havia participado da alegria de ver seu boi ser campeão e, portanto, tinha idéia do que significava, para ela, a derrota do boi Caprichoso.

Concluída essa releitura do conjunto das cartas, cuidei de preparar novamente a rede, o caniço e o anzol, refinando-os para uma grande pescaria, afinal, era chegada a época da piracema - época em que os grandes cardumes de peixes arribam para as nascentes dos rios. Depois de alguns ensaios em pequenas pescarias (as cartas), era, enfim, chegado o momento de tentar refinar os instrumentos de pesca para o grande momento da pesquisa - minha ida a Parintins para o reencontro com os habitantes do lugar, mais especificamente com as minhas parceiras, professoras-leitoras, mas também com seus pais, mães, maridos, avós e ex-professores(as) - um conjunto de "outros" em torno dos quais as professoras se teceram como leitoras.

História de pescadora-pesquisadora: caminhando para o fim... Após vários rascunhos, consegui estabelecer alguns focos temáticos que pudessem servir como um roteiro, visando não apenas imprimir uma certa direção às narrativas das professoras - auxiliando-as a organizar os seus depoimentos -, mas também tentando desencadear o próprio processo de rememoração do percurso vivido por elas. Preparei os focos para uma entrevista semidirigida (com alguns pontos de destaque delimitados a priori), por um lado, pensando que, a partir desse roteiro, as minhas parceiras pudessem fazer o relato temático de suas histórias de vida direcionado mais especificamente para os momentos vividos em relação à sua formação de professora e de leitora; por outro lado, pretendendo que esse roteiro me servisse como um mapa orientador das informações que 
precisaria recolher posteriormente.

Com esses focos, pretendia levantar informações sobre, entre outras coisas: a leitura na infância e na adolescência; a leitura na vida pessoal/ profissional; a leitura em família; modelos e influências de leitores; maneiras de se relacionar com o objeto escrito; disponibilidade do livro e outros suportes escritos na cidade; estratégias de acesso; dificuldades e facilidades para ler; a formação escolar; a trajetória de carreira; o aprender a ensinar; relação entre o crescimento pessoal/profissional; modelos que influenciaram a prática de professora; crenças, valores e opiniões (sobre educação, leitura de mais e menos valor, bom livro/mau livro, bom leitor/ mau leitor). Esses focos foram buscados nas leituras dos autores já referenciados na primeira parte do trabalho e, também, no contato com outros interlocutores em cursos e orientações partilhadas, mas, principalmente, nas informações que consegui obter através das cartas que havia trocado com as minhas parceiras.

A reconstrução da experiência vivida pode revelar-nos uma trilha de formação, que quase sempre nos passa desapercebida. As histórias de professores têm o que contar para ajudar na formação de outros professores. Quando li aquelas cartas, recuei no tempo, tentando lembrar de minha prática como formadora daquelas professoras: o que teria feito (sem perceber), na disciplina que havia ministrado em 1986 no curso de Letras, para despertar o interesse daquelas professoras para a leitura? Comecei a pensar que a minha própria história também pode indicar caminhos que ajudem a formar leitores(as)-professores(as). Sozinha não consigo (mesmo distanciada no tempo) perceber, com clareza, qual foi a atividade desenvolvida ou comportamento assumido por mim, que funcionou como elemento disparador para despertar/estimular uma relação de prazer das ex-alunas com o livro, a leitura. Ao ler os fragmentos de histórias, registrados nas cartas, via-me ruminando sobre minha história de leitora-professora e a ligação da mesma com outras histórias, com outros(as) leitores(as).

Ao mesmo tempo, o conjunto de vozes confrontava-me com a minha própria história de formação de leitora-professora. Comecei a perceber que a dimensão formadora da minha investigação (as narrativas de formação das professoras) atingia-me, visto que não apenas as professoras reconstituíam os seus caminhos - eu também. Aquelas narrativas suscitavam ecos e transportavam-me para a minha história, estimulando uma reflexão mais apurada dos acontecimentos e representações que emergiam da minha memória. Em relação a isso, $\operatorname{Kramer}(1994$, p.15) assinala que:

[...] a história de vida de um dado professor ou professora não se esgota nos seus aspectos idiossincráticos ou únicos, mas permanece em estado de tensão com os fatos ou acontecimentos que encontram eco no 'outro' e em suas possíveis histórias. Trata-se, portanto, de encontrar, nas narrativas tiradas das entrevistas, as 'ressonâncias' ou o 'eco' de uma vida em outras vidas, recuperando sempre nas diferentes 
falas dos professores aquilo que diz respeito a um tempo saturado de 'agoras'.

As narrativas escritas (cartas) tanto quanto as orais (entrevistas), recolhidas pelo movimento da pesquisa, trouxeram à tona esse entrecruzamento de histórias de leitoras-professoras que, em alguns momentos, assemelham-se e, em outros, diferenciam-se, num movimento natural de histórias que são marcadas também por outras vozes e por diferentes tempos, espaços e trilhas percorridas.

Concluindo o relato desta experiência de usar cartas na pesquisa, o que fica? Inicialmente, sinto-me à vontade para dizer o que me tem sido ressoante do texto de Fazenda \& Soares (1992) sobre "Metodologias nãoconvencionais em teses acadêmicas".

Convoco, então, esse texto para auxiliar-me a desenvolver a seguinte idéia: se o uso de cartas na pesquisa pode ser considerado como uma prática pouco convencional porque ainda é reduzido o número de investigações que lançam mão desse meio de comunicação como um instrumento que se junte a outros para recolher os dados - então, essa fala de Soares vem reforçar minha compreensão no sentido de que:

Entre o convencional e o não-convencional, em pesquisa e produções acadêmicas, não cabem juízos de valor. Não se trata de valorizar o não-convencional e desvalorizar o convencional, nem cabem aqui comparações maniqueístas. Na verdade, convencional ou não-convencional não é propriamente a metodologia de pesquisa, é a maneira como as pessoas vêem a metodologia. Creio que não é absurdo dizer que todas as metodologias de pesquisa são válidas e importantes, tudo dependendo do objeto da pesquisa e das opções do pesquisador. (Fazenda \& Soares, 1992, p.127)

Afora isso, é possível compreender o uso das cartas como uma estratégia que provoca um deslocamento na maneira como as professoras percebem e informam suas experiências de ensinar a leitura e a escrita. A proposição das cartas como o recurso por meio do qual suas vivências enquanto professoras-leitoras-autoras seriam transmitidas, colocou-as de frente com a situação de praticantes, de fato, da escrita e da leitura. Isso possibilitou, entre outras coisas, a reflexão sobre os seus modos de se relacionarem com a cultura escrita.

Além disso, esta pesquisa, ao utilizar a carta como um instrumento de coleta de dados, usa-a, ao mesmo tempo, como um recurso que possibilita o exercício da leitura e da escrita para a pesquisadora e para as pesquisadas. Por isso, revelou-se como uma alternativa de autoformação para quem envolveu-se com/e na prática de pesquisar histórias de quem ensina e tem como interesse de investigação o ler e o escrever. 


\section{Referências}

ANDRADE, M. A lição do amigo: cartas de Mário de Andrade a Carlos Drumond de Andrade, anotadas pelo destinatário. Rio de Janeiro: J. Olympio, 1982.

ANDRADE, M. Cartas a Anita Malfatti. Org. Marta Rossetti Batista. Rio de Janeiro: Forense Universitária, 1989.

ANDRADE, M. Cartas de Mário de Andrade a Oneyda Alvarenga. São Paulo: Duas Cidades, 1983.

ANDRADE, M. Cartas a um jovem escritor: Mário de Andrade a Fernando Sabino. 2.ed. Rio de Janeiro: Record, 1982.

ANDRADE, M. Cartas a Manuel Bandeira. Rio de Janeiro: Tecnoprint, 1967.

ANDRADE, M. Cartas a Manuel Bandeira. Rio de Janeiro: Tecnoprint, 1958.

BAKHTIN, M. Os gêneros do discurso. 2.ed. In: Estética da criação verbal. São Paulo: Martins Fontes, 1997. p.277-326.

DEMARTINI, Z. B. F. Histórias de vida na abordagem de problemas educacionais. In: SIMSON, O. (Org.) Experimentos com histórias de vida. São Paulo: Vértice, 1988. p.44-71.

DEMO, P. Introdução à metodologia da ciência. 2.ed. São Paulo: Atlas, 1985.

FAZENDA, I.; SOARES, M. Metodologias não-convencionais em teses acadêmicas. In: FAZENDA, I. (Org.) Novos enfoques da pesquisa educacional. São Paulo: Cortez, 1992. p.119-28.

KRAMER, S.; SOUZA, S. Experiência humana, história de vida e pesquisa: um estudo da narrativa, leitura e escrita de professores. In: REUNIÃO ANUAL DA ANPEd, 17., 1994, Caxambu. Texto apresentado... Caxambu, 1994.

MELO, T. Faz escuro mas eu canto. Rio de Janeiro: Paz e Terra, 1975.

MORAES, A. A. A. Histórias de leitura em narrativas de professores: uma alternativa de formação. 1999. Tese (Doutorado) - Universidade Federal de São Carlos, São Carlos.

NUNES, C.; CARVALHO, M. M. C. Historiografia da educação e fontes. Cad. Anped, n.5, set. 1993. ROCHA, Z. Abelardo-Heloísa: cartas. Recife: Ed. UFPE, 1997.

SANTOS, N. P. T. A carta e as cartas de Mário de Andrade. Rio de Janeiro: Diadorim, 1994.

VENCIO, E. Carta entre os Jarawara: um estudo da apropriação da escrita. 1996. Dissertação (Mestrado) - IEL, Universidade de Campinas, Campinas. 


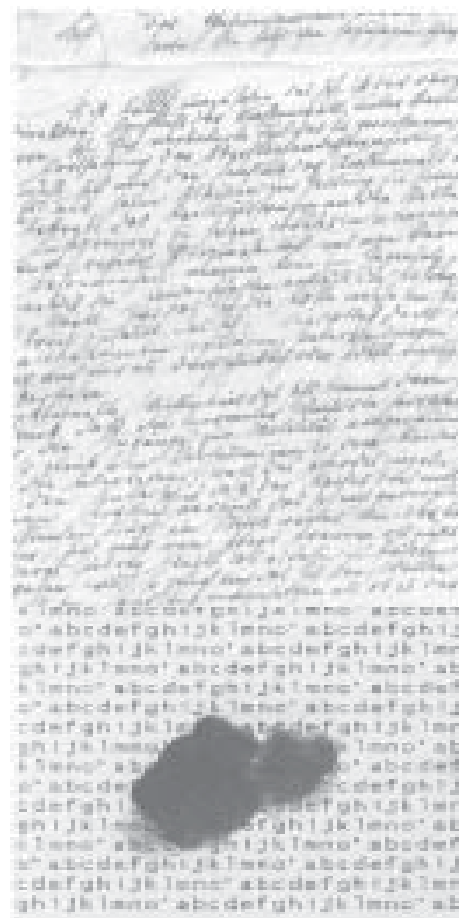

MORAES, A. A. A. Red de pesca: el uso de carta en investigación. Interface - Comunic., Saúde, Educ., v.10, n.19, p.169-84, jan/jun 2006.

El texto comparte una experiencia que usa la carta como uno de los recursos para recolectar información en investigaciones. El camino recorrido, en el período de 1996 a 1997, constó de 16 cartas enviadas por la investigadora y 13 cartas como respuesta de las profesoras que componían los sujetos investigados. La carta, misiva o epístola ha sido un recurso poco utilizado en investigación, aunque algunos estudios indiquen que más recientemente su uso está creciendo. Las cartas, recolectadas por el movimiento de esa investigación, revelaron un entrecruzamiento de historias de lectoras-profesoras que, en algunos momentos, se asemejaban $y$, en otros, se diferenciaban, en un movimiento natural de historias que son marcadas también por otras voces y por diferentes tiempos, espacios y caminos recorridos. El uso de la carta se haya revelado como un género que estableció eslabones de encantamientos, entrecruzamiento de relaciones afectivas y culturales entre la investigadora, profesoras y alternativas de autoformación.

PALABRAS CLAVE: correspondencia. enseñanza. educación. 